\title{
UNDERLYING FACTORS OF ATTITUDE AND INTENTION TOWARDS KNOWLEDGE SHARING AMONG EMPLOYEES: THE CASE OF THE HOTEL BUSINESS IN AMBON, INDONESIA
}

\author{
Join Rachel Luturmas \\ Politeknik Negeri Ambon, Indonesia \\ (jluturmas@yahoo.com)
}

Nurul Indarti

Faculty of Economics and Business, Universitas Gadjah Mada, Indonesia

(nurulindarti@ugm.ac.id)

\begin{abstract}
Studies into knowledge sharings' attitudes and intentions, in the context of the hotel industry, have received relatively little attention. This current study is intended to fill that void and contribute to the existing discussion of knowledge sharing studies of hotel businesses. The main objective of the current study is to examine: 1) the effect of extrinsic motivation, absorptive capacity, channel richness and sense of self-worth on people's attitude towards knowledge sharing, and 2) the effect of people's attitudes towards knowledge sharing and the intention to share knowledge. The study mainly uses the Theory of Reasoned Action (TRA) as the point of departure to understand the attitude and intention of knowledge sharing. It also proposes six hypotheses. We conducted a survey among 300 employees from various hotels in the city of Ambon, Indonesia. The data are tested using Structural Equation Modelling (SEM) techniques. The findings substantiate theoretical discussions and previous studies. The extrinsic motivation, absorptive capacity, and in-role behaviour have a positive effect on the attitude towards sharing knowledge. In addition, the attitude to knowledge sharing has a positive influence on the intention to share knowledge. Meanwhile, the effect of channel richness and the sense of self-worth on the attitude to knowledge sharing are not supported. The study also provides suggestions for hotel businesses to offer extrinsic rewards and improve their employees' skills in order to enhance the employees' absorptive capacities.
\end{abstract}

Keywords: attitude, intention, knowledge sharing, hotel business, Ambon

\section{INTRODUCTION}

Nowadays, many organisations are forced to formulate appropriate strategies to anticipate and beat their competitors. Various factors such as the ability to manage human resources, information technology and knowledge are considered as key ingredients for a company's success (Cabrera and Cabrera, 2005). Those interlocking factors result in companies having the capability to improve their stock of knowledge by stimulating their employees to share knowledge with others, both inside and outside of the company.

Several authors (e.g. Liebowitz, 2003; O'Dell and Grayson, 1998 in Kwok and Gao, 2005) argue that knowledge sharing is an effec- tive approach to gain company competitiveness. Knowledge sharing is defined as an exchange of ideas, experiences, and thoughts among individuals (i.e. Ismail et al., 2009). This means that every individual, group, team, or division within an organisation has different knowledge and shares this knowledge to gain added value for the organisation. Moreover, Szulanski (1995) proposes four main factors determining an effective process of knowledge sharing: a) the reliability of the source of knowledge; b) the motivation for knowledge sharing; c) the capacity to learn (new) knowledge; and d) the capacity to apply new knowledge. One of the biggest challenges in managing knowledge within an 
organisation is changing the attitudes of its employees, so that the employees realise that sharing knowledge has benefits for their jobs (Ruggles, 1998; Bock et al., 2005).

From a knowledge-based view of a firm, when an employee is aware and understands that sharing her/his knowledge is a part of the employee's duties in their work place, he/she has a better attitude towards knowledge sharing. This is called in-role behavior, meaning that one plays the role expected of them (e.g. Gross et al., 1958; Teh and Yong, 2011). When this role is regarded as a duty, an employee tends to carry it out, rather than when it is regarded as an additional task (Morisson, 1994). In the context of a knowledge-based organisation, an activity is defined as in-role behavior when employees apply knowledge sharing as a normal part of their behaviour at work.

Knowledge sharing's attitude influences the intention to share knowledge (Lin, 2007). Employees who are willing to share knowledge with their colleagues are encouraged to repeat this behavior so that consequently their intention to share their knowlegde is increased (Wu and Sukoco, 2010). When employees have a better attitude towards knowledge sharing, they have a greater intention to share their knowledge. This knowledge sharing attitude is considered to exist if any employees share their knowledge with other colleagues within the company (Ryu et al., 2003). Such an attitude comes from someone's feeling, either positive or negative, towards their intended sharing behavior (Bock et al., 2005).

The current study uses the Theory of Reason Action (TRA) to explain that a certain behavior is determined by the way it responds to other behavior (Fishbein and Ajzen, 1975; Korzaan, 2003). People tend to behave in one way when they are influenced by a positive attitude, and in an opposite manner when influenced by a negative attitude. Based on this TRA, in the context of knowledge sharing, if an employee perceives that knowledge sharing is a positive thing, and then he/she also tends to share knowledge with other employees.

The activity of sharing knowledge occurs not only in manufacturing companies but also applies in service industries such as telecommunications, transportation, banking, and even in fast growing business such as the hospitality sectors (Zeithaml and Bitner, 2003). The hotel industry and other service industries such as restaurants, accommodation, entertainment, and transportation are currently facing stiffer competition (Brotherton, 1999) that forces them to have good systems for knowledge management, particularly knowledge sharing. From the literature on knowledge sharing, the vast majority of the studies have been conducted in the context of manufacturing industries, little attention has been paid to the service industries including hotels, restaurants, and tourism (see: Hallin and Marnburg, 2006; Hu et al., 2009).

In Indonesia, within the last five to ten years, there has been rapid growth in the hotel industry, including in eastern Indonesia. In Ambon, there are 13 star hotels, three of them are 4-star hotels that were established within the last five years. In addition, Ambon is one of the preferred tourist destinations and has great potential for the hotel business (Media Indonesia, 2009). According to the Indonesian Statistic Bureau (Province of Maluku, 2016), the number of both domestic and foreign tourists visiting Ambon increased dramatically in the last three years. As an illustration, the number of tourists in 2011 was 4,509 visitors, which increased significantly in 2015 to 6,685 , with the annual number of tourists during the period from 2011-2015 averaging 5,335 persons. Based on these numbers, we may argue that the increasing number of tourists have galvanised people in the hotel industry there to provide appropriate accommodation and services to the tourists. The services available are indeed based on knowledge ( $\mathrm{Hu}$ et al., 2009), thus it is important to study the influence of the attitude and intention of the employees' toward sharing their knowledge of their work activities. The results of the current study are beneficial for the development of the hotel industry, particularly in eastern Indonesia.

Based on the above discussion, the current study is essential because of some background information. First, the number of prior studies on the factors determining the attitude and intention 
to share knowledge in the hotel industry is relatively limited (see: Hallin and Marnburg, 2006; Hu et al., 2009). Second, there are still some inconsistencies in the prior studies about the factors affecting the attitude to knowledge sharing (Bock et al., 2005; Kwok and Gao, 2005; Burgess, 2005; Galia, 2006, Wasko and Faraj, 2005; Teh and Yong, 2011), especially the factors of extrinsic motivation and the sense of self-worth. These lead us to study those factors in order to test and re-validate them with special reference to the hotel industry. Third, many studies on the attitude and behavior to knowledge sharing have been done in many various ways, i.e they have used various independent variables such as: a) extrinsic motivation (e.g. Bock et al., 2005; Kwok and Gao, 2005; Burgess, 2005; Galia, 2006); b) absorptive capacity (see: Kwok and Gao, 2005); c) channel richness (e.g. Kwok and Gao, 2005; Murray and Peyrefitte, 2007); d) sense of self-worth (e.g. Bock et al., 2005; Wasko and Faraj, 2005; Teh and Yong, 2011), and e) in-role behavior (e.g. Teh and Yong (2011). Other previous studies (i.e. Bock and Kim, 2002; Lin, 2007; Hsu and Lin, 2008; and Teh and Yong 2011) treated the knowledge sharing attitude as an independent variable of knowledge sharing's intent.

The current study was intended to integrate the various factors of knowledge sharing's attitudes in the context of the hotel industry. The study aims to answer the following six questions: 1) does extrinsic motivation have a positive influence towards a knowledge-sharing attitude? 2) Does absorptive capacity have a positive influence towards a knowledge sharing attitude? 3) Does channel richness have a positive influence towards a knowledge sharing attitude? 4) Does a sense of self-worth have a positive influence towards a knowledge sharing attitude? 5) Does in-role behavior have a positive influence towards a knowledge sharing attitude? 6) Does a knowledge sharing attitude have a positive influence towards knowledge sharing's intention? The study is expected to contribute to the literature on knowledge sharing by adding empirical findings in the context of the hotel industry.
This article consists of five parts. The first part is the introduction. The second part discusses the theories and hypotheses formulation. The research methods are presented in the third part. The fourth part presents the analyses of the research results and hypotheses tests. The last part contains the discussion, conclusions, implications, limitations, and suggestions for future research.

\section{Literature review and hypotheses development}

This current study on knowledge sharing among employees is based on the theory of reasoned action (Ajzen and Fishbein, 1980), which explains that human beings will behave rationally (Davis et al., 1989). Humans have a logical thinking mechanism which allows them to decide what to do (Ramayah et al., 2004). This theory claims that basically one behaves cognizantly, has both explicit and implicit considerations for behaviour, and is aware of the implications of one's behavior. In short, behavior occurs because there is an intention to act.

Intention is the will to commit a certain act (e.g. Ajzen and Fishbein, 1980; Hartono, 2007), but does not yet carry it out (Hartono, 2007). In the TRA, Fishbein and Azjen (1980) explain that acts can be committed when one has an intention to commit (behavioral intention). Behavioral intention determines whether a certain act will take place or not. Behavioral intention is a good predictor of intended behavior. Intention will determine an action, and it is more powerful than tendencies (Fishbein and Azjen, 1980; Hartono, 2007).

Moreover, intention refers to two factors: first, the personal factor i.e. a person's attitude towards behavior; and second, the social factor i.e. subjective norms (see Ajzen and Fishbein, 1980). The personal factor means a person's manner towards an attitude that evaluates someone's trust or positive/negative feelings. An employee is willing to commit a certain type of act when he/she believes that it is a positive thing. In the frame of knowledge sharing, an employee is aware when sharing knowledge. The social factor is the subjective norm that 
relates to a perception or assumption towards social pressure.

This study highlights individual aspects i.e. employees' knowledge sharing within an organization. An individual has the cognitive capacity (Nooteboom, 2000) to judge every decision upon considerated behavior. Thus, the RAT (Ajzen and Fishbein, 1980) is considered able to specifically explain the personal factors affecting an employee's decision, e.g. extrinsic motivation, absorptive capacity, channel richness, sense of self worth, and in-role behavior, for sharing their knowledge.

This study aims to test the factors that determining the attitudes to knowledge sharing, e.g. the extrinsic motivation, absorptive capacity, channel richness, sense of self worth, and in-role behavior, on the attitude to knowledge sharing. At the same time, the study also examines the effect of the attitude towards knowledge sharing on the intention to share knowledge, simustaneously. Each factor will be discussed in detail in the following sub headings.

\section{Extrinsic Motivation}

Extrinsic motivation is defined as an action performed to gain different outputs (Ryan and Deci, 2000). The action is not solely intended to accomplish the goal itself (Kruglanski, 1978; Ryan and Deci, 2000; Vallerand and Bissonnette, 1992). In an organization, extrinsic motivation can be in the form of punishments and rewards for certain attitudes (Ryan and Deci, 2000). Extrinsic motivation can be used to encourage or prevent various attitudes which support or are against the existing rules (Ryan and Deci, 2000).

Moreover, extrinsic motivation is often used as a strategy to develop and stimulate a knowledge sharing attitude within an organization. This strategy will be effectively implemented in a situation where there are more creative tasks, tighter monitoring, and more detailed rules on behaviour. Usually, an employee has to consider the costs and benefits of any interactions he/she makes (Cabrera and Cabrera, 2005). In the context of knowledge sharing, an employee is motivated to continue to share knowledge when the interaction gives benefits. An organization provides various ways to facilitate the knowledge sharing, such as providing rewards, compensation, promotion, and also recognition by one's colleague's (Cabrera and Cabrera, 2005).

In short, extrinsic motivation in the form of rewards will increase the employees' motivation to share knowledge with others. Hence, the first hypothesis to test is:

\section{H1: Positive extrinsic motivation affects the knowledge sharing attitude}

\section{Absorptive Capacity}

Knowledge sharing is a reciprocal process between a knowledge giver and a knowledge receiver (Kwok and Gao, 2005). The capability of the receiver to absorb knowledge from the knowledge source is called the absorptive capacity (Cohen and Levinthal, 1990). When the receiver fails to learn and absorb the (new) knowledge, he/she fails in the learning process of knowledge sharing.

Cohen and Levinthal (1990) define absorptive capacity as the capability to absorb new knowledge from others, integrate it with one's existing knowledge and at the same time use it. In addition, Zahra and George (2002) state that absorptive capacity consists of the capability to integrate, acquire, transform, and exploit knowledge. Absorptive capacity reflects the capability of an individual to learn and apply new knowledge which affects that individual's performance. Thus the absorptive capacity of an individual is determined by their existing knowledge, which is determined by their educational background, age, and work experience (Zahra and George, 2002). It is obvious, that different personal backgrounds result in different levels of absorptive capacity. Those who have a high capability to absorb knowledge and are highly competitive tend to favor knowledge sharing (Zahra and George, 2002). Hence, the second hypothesis is formulated as follows:

H2: Absorptive capacity has a positive effect on the knowledge sharing attitude 


\section{Channel Richness}

The process of knowledge sharing needs a communications media to transfer the knowledge from the sender to the receiver. The various communications media used to transfer information from sources to receivers, either verbally or non-verbally, are called channel richness (Murray and Peyrefitte, 2007). Channel richness represents the provision of various communications media for the process of knowledge sharing. Various ways to share knowledge are used such as daily dialogues through phone conversations, discussions, or internet conversations (e.g. Kwok and Gao, 2005).

Robertson et al. (1996) states that channel richness can help an organization's members find and share knowledge with each other at any time and in every place. The richness of the channel enables the members of the organization to have a comfortable and flexible knowledge sharing. The higher the richness of the channel is for sharing knowledge, the more comfortable the individuals are to share their knowledge. Based on the above discussion, the third hypothesis is stated as follows:

H3: Channel richness positively affects the knowledge sharing attitude

\section{Sense of self-worth}

The theory of interaction and cognitive orientation in sociology explains that the reason for human beings conducting interactions is because of their desire to be respected, to gain social status and to be honoured (Wasko and Faraj, 2005). One shares knowledge with others to increase one's sense of self-worth, or one's reputation in an organization.

The sense of self-worth is considered to be a reflection of a person's competence, status, and valuable moral attitudes in the eyes of his/her colleagues (Bock et al., 2005). The sense of selfworth is one of the concepts of self-identity. Burns (1979) says that the self-identity concept is an image of what we think about ourselves, and what we want.
In managing work within an organization, a group's knowledge sharing involves an intensive and continuous interaction, providing information or job descriptions, and receiving comments from superiors about the work done (Cummings, 2004). When an employee carries his/her work out as expected, the process of knowledge sharing will improve and continue. Therefore, employees who have high levels of self-esteem tend to develop a positive attitude to sharing knowledge.

Good feedback is very important for knowledge sharing activities. The more intense the exchange of information is, the more obvious the role of each individual is (Kinch, 1973). This contributes to the growth of a sense of self-worth resulting in more effective performance. Individuals who receive feedback from knowledge sharing activities are more willing to contribute to the process of knowledge sharing. Consequently, this condition increases the individuals' sense of self-worth. They understand that an active involvement in knowledge sharing activities can be beneficial for other individuals within the organization and the organization itself. Individuals who have a sense of self-worth will have positive feelings towards the knowledge sharing attitude. Hypothesis four is then formulated as follows:

\section{H4: The sense of self-worth positively affects the} knowledge sharing attitude

\section{In-role behaviour}

In-role behaviour is the attitude to performing work as it is expected to be done by what is contained in the job description ((Gross et al. (1958); van Dyne and LePine (1994); Teh and Yong (2011)). In-role behavior is often related to rewards and punishments. An employee does his work based on his responsibilities, which are specified in his job description, and is motivated to gain rewards and to avoid sanctions when failures take place. It can be then concluded that giving rewards and punishments are very influential to the successful outcome of any employees' work. The higher the rewards and the heavier the sanctions for the employees, the 
higher the motivation of the employees will be to improve their working performances for the advancement of the organization (Teh and Yong, 2011). On the contrary, when the reward is considered to be low and the punishment weak, the motivation will also decrease and consequently decreases the employees' performance.

Rewards and punishments are a part of the in-role behavior activities. It means that when an employee feels that knowledge sharing is part of his/her responsibilities, he/she will have a better attitude towards knowledge sharing. On the other hand, when an employee feels that knowledge sharing is not a part of his/her job, he/she will have less of an inclination towards knowledge sharing. We may conclude that in-role behavior affects the employees' attitude towards knowledge sharing. Hence, hypothesis five is formulated as follows:

H5: In-role behavior positively affects the knowledge sharing attitude

\section{Knowledge sharing attitude}

According to the RAT, attitude is found to have a significant influence on the intention to share knowledge (Lin, 2007). Individuals who intend to share and participate in group discussions are more likely to repeat this behavior with greater enthusiasm (Wu and Sukoco, 2010). The RAT explains how one's behavior is affected by the intention to do something. One's intention is determined by one's attitude. Thus, the intention to share knowledge is determined by the knowledge sharing attitude.

In the context of individual behavior, a more beneficial attitude to sharing becomes an indicator to knowledge sharing. Behavioral intentions are a function of attitudes. Attitude is the evaluation of trust, or an individual's positive/negative feelings to committing certain behavior. The more positive an individual's attitude is towards knowledge sharing, the more intention he/she has of sharing knowledge. Based on these arguments, the sixth hypothesis is stated as follows:
H6: The knowledge sharing attitude positively affects the knowledge sharing intention

All the six hypotheses are depicted in Figure 1.

\section{Operational Definitions and Measurement}

The variables used in this study are an endogenous or dependent variable and exogenous or independent variables. The independent variables used to test the first five hypotheses (H1 to H5) are: (a) extrinsic motivation; (b) absorptive capacity; (c) channel richness; (d) sense of self-worth; and (e) in-role behavior, while the dependent variable is the attitude to knowledge sharing. Moreover, the attitude to knowledge sharing is treated as the independent variable to test Hypothesis 6 (H6), and the intention to share knowledge is the dependent variable. The operational definitions of all the variables are summarized in Table 1.

\section{Research Methodology}

\section{Sampling and Data Collection Techniques}

This study applies an explanatory quantitative approach using an instrument (i.e. a questionnaire). As the objective of the study is to examine the level of the attitude towards knowledge sharing and the behavior of the employees, we use a purposive sampling method to select suitable respondents (Cooper dan Schindler, 2011). The respondents are 325 employees from 13 hotels in the city of Ambon, who all have at least one year's experience of knowledge sharing. Those 13 hotels comprised of: two 1-star hotels, five 2-star hotels, five 3star hotels and one 4-star hotel.

Data were collected over a four month period (March-June 2012) using face-to-face interviews to ensure the response rate. Not surprisingly, the response rate was very high (100\%). All filled questionnaires were $100 \%$. Among them, 25 questionnaires were rejected due to having incomplete answers. The majority of the respondents were male $(65.67 \%)$, aged between 21 and 35 years old $(77.67 \%)$, and had at least a senior high school level of education $(80,33 \%)$, as shown in Table 2. 


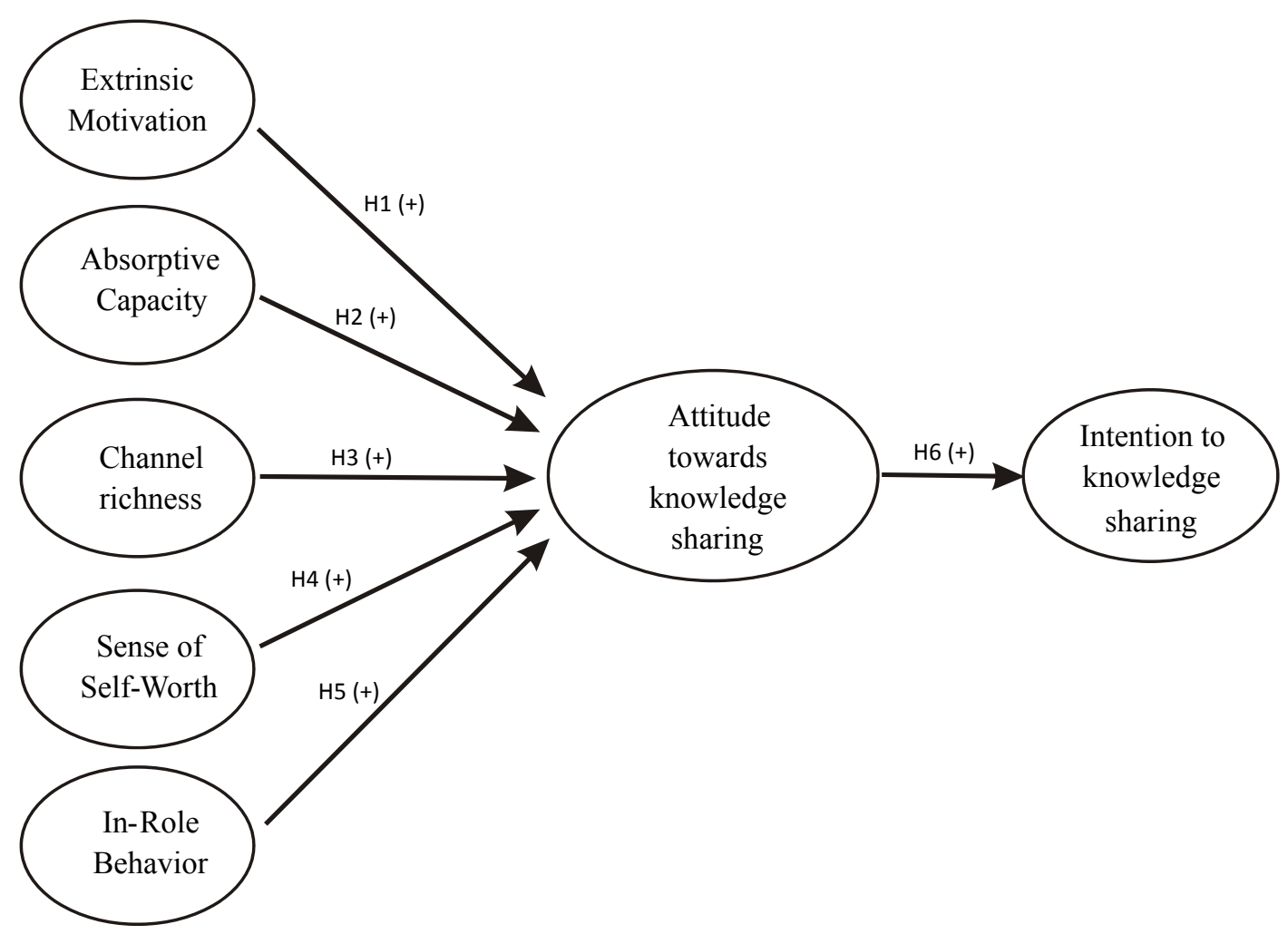

Figure 1. Research Model

Table 1. Variables and Operational Definition

\begin{tabular}{|c|c|c|c|}
\hline No & Variables & Operational Definition & Item \\
\hline 1. & Extrinsic motivation & $\begin{array}{l}\text { Drivers to gain certain goals or rewards such as increased } \\
\text { tasks, wages, promotion, etc. }\end{array}$ & 3 \\
\hline 2. & Absorptive capacity & Capability to obtain, assimilate, and apply knowledge & 3 \\
\hline 3. & Channel richness & $\begin{array}{l}\text { Types and width of communications media used for verbal } \\
\text { or non-verbal communications to facilitate knowledge } \\
\text { sharing from sender to receiver }\end{array}$ & 3 \\
\hline 4. & Sense of self worth & $\begin{array}{l}\text { Positive belief in contributing to the organization through } \\
\text { the sharing of knowledge }\end{array}$ & 5 \\
\hline 5. & In-role behavior & (Real) attitude to working as is expected & 6 \\
\hline 6. & Knowledge sharing attitude & One's positive/negative feeling towards intended attitude & 4 \\
\hline 7. & $\begin{array}{l}\text { Knowledge sharing } \\
\text { intention }\end{array}$ & One's willingness to share knowledge & 4 \\
\hline \multicolumn{3}{|c|}{ Total Items } & 28 \\
\hline
\end{tabular}

Source: Kwok and Gao (2005); Teh and Yong (2011) 
Table 2. Demographics of respondents

\begin{tabular}{llcc}
\hline \multicolumn{1}{c}{ Item } & \multicolumn{1}{c}{ Category } & No. of respondents & Percentage \\
\hline Gender & Male & 197 & $65.67 \%$ \\
& Female & 103 & $34.33 \%$ \\
& A 20 years & 21 & $7.00 \%$ \\
& 21 to 35 years & 233 & $77.67 \%$ \\
& 35 to 50 years & 44 & $14.67 \%$ \\
& 51 to 65 years & 1 & $0.33 \%$ \\
& > 65 years & 1 & $0.33 \%$ \\
& Junior high school & 8 & $2.67 \%$ \\
& Senior high school & 241 & $80.33 \%$ \\
& Diploma & 30 & $10.00 \%$ \\
& Bachelor & 19 & $6.33 \%$ \\
& Master & - & - \\
& Doctor & 1 & $0.67 \%$ \\
\hline
\end{tabular}

\section{Validity and Reliability Test}

Table 3 shows that the respondents' responses are valid. The responses to the seven variables all scored highly on a 5-point Likert scale. The study uses face validity and convergent validity. All the variables and items were taken from previous empirical research (i.e. Kwok and Gao, 2005; Teh and Yong, 2011). Based on this, we conclude that the instrument of the study has fulfilled the terms for face validity (Hair et al., 2010). Convergent validity is shown by the Average Variance Error value (AVE) (all scores for each variable have to be above 0.5) (Hair et al., 2010: 709). Based on the findings, we conclude that the items used in this study meet the convergent validity. Table 3 also depicts the scores for Cronbach's alpha. All the variables in the study have a score of above 0.7 for Cronbach's alpha, which means that the instruments used in this study are reliable (Hair et al., 2010).

\section{Data Analysis Methods}

The hypotheses in this study were tested using the Structural Equation Model (SEM). This was chosen as the study required a model capable of testing for relationships among latent contructs, manifested in endogenous and exogenous variables at the same time. SEM is also useful to explain possible measurement errors in the estimation process (Hair et al., 2010:711), which the regression model cannot.
Before testing the hypotheses, we conducted an analysis of the measurement model using Confirmatory Factor Analysis (CFA) to fulfill the criteria of goodness of fit (see Table 4). In the CFA, when an indicator of constructs shows a significant estimated value on the measured constructs, it can be used in a structural model analysis. The results show that all the estimated values of the relation between indicators and constructs are significant at the level of 0,1 . Based on this, the various models we use in this study have good adjustments. Therefore, the models can be used for the next step (i.e. hypotheses testing).

\section{Hypotheses Testing and Discussion}

After the GoF criteria for the structural model are fulfilled, the next step is analysing the relationships of the structural models for the hypotheses tests (see the initial model; modified $\# 1$; modified \#2; and the path analysis). Hypotheses tests refer to the critical ratio values resulting from the regression weights calculations for each inter-construct relationship within the research model. The results show that, in the initial model, only the inter-constructs connection is significant i.e. the extrinsic motivation and in-role behavior towards the knowledge sharing attitude, and the knowledge sharing attitude towards the knowledge sharing intention. We then modified the structural models (modified \#1 and modified \#2) with the aim of getting the most appropriate alternative model to explain the reality of the objects. 
Table 3. Responses of the respondents, reliability, and validity test

\begin{tabular}{|c|c|c|c|c|c|c|c|c|}
\hline No & Variabel & Mean & SD & $\begin{array}{c}\text { Cronbach } \\
\text { Alpha }\end{array}$ & $\begin{array}{l}\text { No. of } \\
\text { items }\end{array}$ & Items & SL & AVE \\
\hline & Extrinsic Motivation [EM] & 4.32 & 0.56 & 0.88 & 3 & $\begin{array}{l}\text { EM1 } \\
\text { EM2 } \\
\text { EM3 }\end{array}$ & $\begin{array}{l}0.79 \\
0.83 \\
0.90\end{array}$ & 0.71 \\
\hline & Absorptive Capacity [AC] & 4.47 & 0.51 & 0.94 & 3 & $\begin{array}{l}\mathrm{AC} 1 \\
\mathrm{AC} 2 \\
\mathrm{AC} 3\end{array}$ & $\begin{array}{l}0.85 \\
0.99 \\
0.92\end{array}$ & 0.84 \\
\hline & Channel Richness [CR] & 4.43 & 0.46 & 0.81 & 3 & $\begin{array}{l}\text { CR1 } \\
\text { CR2 } \\
\text { CR3 }\end{array}$ & $\begin{array}{l}0.73 \\
0.73 \\
0.85\end{array}$ & 0.60 \\
\hline & Sense of Self -Worth [SSW] & 4.59 & 0.49 & 0.83 & 5 & $\begin{array}{l}\text { SSW1 } \\
\text { SSW2 } \\
\text { SSW3 } \\
\text { SSW4 } \\
\text { SSW5 }\end{array}$ & $\begin{array}{l}0.52 \\
0.52 \\
0.80 \\
0.92 \\
0.78\end{array}$ & 0.53 \\
\hline & In-Role Behavior [IRB] & 4.44 & 0.48 & 0.83 & 6 & $\begin{array}{l}\text { IRB1 } \\
\text { IRB2 } \\
\text { IRB3 } \\
\text { IRB4 } \\
\text { IRB5 } \\
\text { IRB6 }\end{array}$ & $\begin{array}{l}0.51 \\
0.73 \\
0.83 \\
0.74 \\
0.62 \\
0.62\end{array}$ & 0.47 \\
\hline & Attitude towards Knowledge Sharing [AKS] & 4.47 & 0.50 & 0.82 & 4 & $\begin{array}{l}\text { AKS1 } \\
\text { AKS2 } \\
\text { AKS3 } \\
\text { AKS4 }\end{array}$ & $\begin{array}{l}0.75 \\
0.81 \\
0.69 \\
0.66\end{array}$ & 0.54 \\
\hline & Intention to Knowledge Share [IKS] & 4.00 & 0.50 & 0.83 & 4 & $\begin{array}{l}\text { IKS1 } \\
\text { IKS2 } \\
\text { IKS3 } \\
\text { IKS4 }\end{array}$ & $\begin{array}{l}0.91 \\
0.72 \\
0.67 \\
0.70 \\
\end{array}$ & 0.57 \\
\hline
\end{tabular}

Table 4. Criteria and Results of Various Models of Goodness of Fit (GoF)

\begin{tabular}{llcccc}
\hline No. & Goodness of Fit criteria & $\begin{array}{c}\text { Structural } \\
\text { Model }\end{array}$ & Modified \#1 & Modified \#2 & Path Analysis \\
\hline 1. & $\chi^{2}$ & 643.313 & 687.878 & 8.596 & 8.227 \\
2. & df & 334 & 383 & 5 & 5 \\
3. & CMIN/df & 1.926 & 1.780 & 1.119 & 1.645 \\
4. & GFI & 0.877 & 0.926 & 0.992 & 0.992 \\
5. & AGFI & 0.850 & 0.862 & 0.955 & 0.957 \\
6. & RMSEA & 0.056 & 0.052 & 0.049 & 0.046 \\
7. & CFI & 0.925 & 0.926 & 0.963 & 0.966 \\
\hline
\end{tabular}

Two types of modification were made to the SEM i.e. modified \#1 (a two-ways approach by reducing the estimated parameter (Hair et al., 2010:730) and modified \#2 (a two-ways approach with a composite, which was continuing the step taken with modified \#1 by accumulating some indicators and changing the unobserved variables to become a single indicator (the composite) (Hair et al., 2010)).
These two modified models also get structural GoF values along with their empirical data (see Table 4). The modified GoF is better than the unmodified GoF (see Table 4).

The significance value of the modified \#1 model is better than the significance value of the unmodified model. However, the significance value of the modified \#2 model is worse than that of the modified \#1 model (Table 2). Based 
on this result, a path analysis was conducted to optimize the SEM modified model. The results of data processing (Table 4) show that the GoF path analysis is better than the GoF modified SEM (modified \#1 and modified \#2). It can be concluded that the structural model analysis with path analysis is valid to test the hypotheses. The results of the hypotheses testing based on the path analysis are summarized in Table 5.

The hypotheses tests show that not all the proposed hypotheses in this study are proven and justify the previous studies. Each hypothesis is discussed in detailed in the following sections.

Hypothesis 1: Extrinsic motivation positively affects the knowledge sharing attitude

This study successfully proves that extrinsic motivation can encourage an employee to share knowledge. As implied in the social exchange theory, employees want to interact with others because of the benefits gained from it (Cabrera and Cabrera, 2005). In the context of a company, employees that get great appreciation or rewards from the company will spend more time sharing their knowledge with others (e.g. Burgess, 2005). Appreciation or rewards become one of the forms of extrinsic motivation to encourage someone to conduct the desired actions (Galia, 2006). Rewards such as increased wages and promotions drive employees to have a positive attitude towards knowledge sharing activities. This proves that employees will do knowledge sharing activities when they get rewards or appreciation for doing them.

Hypothesis 2: Absorptive capacity positively affects the knowledge sharing attitude
In conducting knowledge sharing activities, employees are required to have a high capability to absorb knowledge and then use it (Cohen and Levinthal, 1990). Absorptive capacity is an individual capability that affects a person's performance during the process of learning and then implementing the knowledge. The absorptive capacity is determined by the capability to absorb knowledge, which can be measured by one's working experience and level of education.

In this study, the level of the absorptive capacity of the hotel employees in Ambon is indicated from their levels of education. Most of the employees graduated from senior high school, as a minimum. This may indicate that they have a good absorptive capacity to enable them to better absorb knowledge. Therefore, they have a good attitude towards knowledge sharing activities. The higher that the capability of the employees to absorb and use knowledge is, the higher their attitude towards knowledge sharing activities will be. Employees believe that knowledge sharing gives them a lot of benefits to improve their capabilities in accomplishing their jobs and tasks in the company. This study supports the above argument.

\section{Hypothesis 3: Channel richness positively affects the knowledge sharing attitude.}

Various communications media are needed to transfer knowledge from senders to receivers. Channel richness refers to the existence and provision of these various ways during the process of knowledge sharing (Kwok and Gao, 2005). The richness of the channel will facilitate and stimulate the organisations' members to acquire and share knowledge within the organisation (Robertson et al., 1996).

Tabel 5. Results of hypotheses testing

\begin{tabular}{llccl}
\hline \multicolumn{1}{c}{ Hypotheses } & EV & CR & \multicolumn{1}{c}{ Noted } \\
\hline H1 & Extrinsic Motivation $\rightarrow$ Attitude toward Knowledge Sharing & 0.072 & $1.709^{* *}$ & Supported \\
H2 & Absorptive Capacity $\rightarrow$ Attitude toward Knowledge Sharing & 0.071 & $1.528^{* *}$ & Supported \\
H3 & Richness of Channel $\rightarrow$ Attitude toward Knowledge Sharing & -0.015 & -0348 & Not supported \\
H4 & Sense of Self-worth $\rightarrow$ Attitude toward Knowledge Sharing & 0.015 & 0.220 & Not supported \\
H5 & In-Role Behavior $\rightarrow$ Attitude toward Knowledge Sharing & 0.450 & $5.277^{* *}$ & Supported \\
H6 & Attitude toward Knowledge Sharing $\rightarrow$ Intention toward & 0.170 & $2.288^{* *}$ & Supported \\
& Knowledge Sharing & & & \\
\hline
\end{tabular}


The result of Hypothesis 3 (H3) fails to prove that channel richness positively affects the knowledge sharing attitude. This result is different from the previous research (e.g. Kwok and Gao, 2005; Murray and Peyrefitte 2007). Kwok and Gao (2005) found that the richness of the channel positively affects the attitude to knowledge sharing. Knowledge sharing can successfully be conducted by the simplest means i.e. daily dialogues. The richness of the channel may result in various different ways that make knowledge sharing activities easier; a great number of channels help people to find knowledge more easily (Robertson et al., 1996). This also enables people, wherever they are and whenever they want, to flexibly and practically share knowledge. The findings of the current study corroborate the previous studies which stated that the more channels used to share knowledge, the more the individuals share knowledge and the more positively they behave towards the process of knowledge sharing.

From the survey, the respondents reported that they share knowledge via limited channels of communication, such as e-mails and face-toface meetings. This may indicate that they have a lack of communication channels for sharing their knowledge in their company. This condition may hinder them in conducting knowledge sharing which may explain why Hypothesis 3 is not supported.

Hypothesis 4: A sense of self-worth positively affects the knowledge sharing attitude

Good feedback is very important for activities like knowledge sharing. The more intense that the exchange of information is, the more obvious the role of each individual appears (Kinch, 1973; Bock et al., 2005). This contributes to the development of self-worth which resulting in effective performance. Individuals who receive good feedback from knowledge sharing activities will be more active in sharing their knowledge in the future. Consequently, this increases the individuals' sense of self-worth.

Knowledge sharing among employees requires a good response. Previous authors (e.g.
Kinch (1973); Bock et al. (2005)) argue that when others respond positively to what we are doing, we think that what we are doing is right and, at the same time, our roles get improved and continue. Based on the results of hypothesis testing for $\mathrm{H} 4$, it shows that a sense of self-worth does not positively affect the attitude to knowledge sharing. The current study does not corroborate the previous studies (e.g. Wasko and Faraj, 2005; Teh and Yong, 2011).

From the face-to-face interviews with the respondents, we found that they start sharing knowledge when there are activities that have positive impacts for their company. Some respondents also state that there is not enough feedback from their company about the knowledge sharing activities they undertook. This situation may result in a loss of the sense of selfworth among the employees, which in turn, may affect the employees' attitude to conducting knowledge sharing. If the employees receive good feedback on what they do, they would think that what they did is right, and so this might increase their role. These arguments may explain the findings.

\section{Hypothesis 5: In-role behavior positively affects the knowledge sharing attitude}

In-role behavior is the attitude to carry out the assigned work, as it is expected to be done in accordance with the job's description (Gross et al., 1958). When something is regarded as part of his/her duties, an employee tends to carry it out, rather than when it is regarded as an additional task or burden (Morisson, 1994). An employee who feels that knowledge sharing is a part of his/her job will have a better attitude towards knowledge sharing. Not surprisingly, the result of Hypothesis 5 proves that in-role behavior positively affects the knowledge sharing attitude. This result is in line with a previous study by Teh and Yong (2011). The findings indicate that employees who work in hotels in Ambon understand that their sharing of knowledge has a big role to play. Therefore, their attitude towards knowledge sharing is positive. 
Hypothesis 6: The knowledge sharing attitude positively affects the knowledge sharing intention

The last hypothesis in this study is H6, which states that the attitude to knowledge sharing positively affects the knowledge sharing intention. Based on the results, we found that the current study confirms the previous studies (e.g. Hsu and Lin, 2008; Liao et al., 2010; Lin, 2007; Teh and Yong, 2011). The employees of the hotels in Ambon show their intention to share their knowledge with others within their organisation. The more positive the attitude of an employee is towards sharing their knowledge, the higher the intention is towards sharing their knowledge. In short, we conclude that the intention to share knowledge is a function of the knowledge sharing attitude.

\section{Conclusion, Contribution, and Suggestions for the Next Research}

In general, the current study provides an empirical contribution about the effects of extrinsic motivation, absorptive capacity, and inrole behavior on the attitude to knowledge sharing, and the effect of this knowledge sharing attitude on the intention to share knowledge, with special reference to a service-factory sector (i.e. the hotel industry). These findings support the previous empirical studies (such as Burgess, 2005; Galia, 2006; Lin, 2007; Hsu and Lin, 2008; Liao et al., 2010; Teh and Yong, 2011). However, channel richness and sense of selfworth are not found to have a positive effect on the attitude towards sharing. The results of this study do not support the research conducted by Kwok and Gao (2005); Murray and Peyrefitte (2007); Wasko and Faraj (2005); and Teh and Yong (2011).

The results of the current study offer both a theoretical contribution and managerial implications. From the theoretical perspective, this study supports and strengthens the previous research into the factors determining the attitude and intention to share knowledge, with special reference to the hotel industry in the eastern part of Indonesia (ie. Ambon). Moreover, the study was intended to test inconsistencies in the findings from previous studies i.e. the effect of extrinsic motivation and the sense of self-worth on the knowledge sharing attitude. From the managerial perspective, the results of this study provide suggestions for companies. For instance, a company can provide extrinsic rewards to encourage and motivate its employees' to share their knowledge. In addition, the company can improve the skills of its employees through workshops and training in order to develop their role within the company and their absorptive capacities.

The study is not without its limitations. The current study utilizes cross-section data that may not be able to capture a change in behavior from attitude to intention. A future study may employ different time spans to observe the real behavior. The setting of the current study is the hotel service sector, which is classified as a servicefactory (see Lovelock, 1983) that represents a low level of employees' interaction, customisation, and intensity. We expect that this study can be generalized to other service factor contexts such as restaurants, recreation areas, and airlines.

\section{REFERENCES}

Argote, L., and P. Ingram, 2001. 'Knowledge Transfer: A Basis for Competitive Advantage in Firms'. Organizational Behavior and Human Decision Processes, 82 (1), 150169.

Bock, G. W., and Y. G. Kim, 2002. 'Breaking The Myths of Rewards: An Exploratory Study of Attitudes about Knowledge Sharing', Information Resources Management Journal, 15 (2), 14-21.

Bock, G. W., R. W. Zmud, Y. G Kim, and J. N., Lee. 2005. 'Behavioral Intention Formation in the Knowledge Sharing: Examining the Roles of Extrinsic Motivators, SocialPsychological Forces, and Organizational Climate'. MIS Quartely, 29 (1), 87-111.

Brotherton, B. 1999. 'Towards a Definitive View of the Nature of Hospitality and Hospitality Management'. International Journal of Contemporary Hospitality Management, 11 (4), 165-173. 
Burgess, D. 2005. 'What Motivates Employee to Transfer Knowledge Outside Their Work Unit?' Journal of Business Communication, 42 (4), 324-348.

Burns, R. B. 1979. The Self Concept in Theory, Measurement, Development, and Behavior. London: Wesley Longman Ltd.

Cabrera, E. F., and A. Cabrera, 2005. 'Fostering Knowledge Sharing Through People Management Practices'. International Journal of Human Resources Management, 16 (5), 720-735.

Cohen, W. M., and D. A. Levinthal, 1990, 'Absorptive Capacity: A New Perspective on Leaming and Innovation'. Administrative Science Quarterly, 35 (1), 128- 152.

Cooper, R. D., and P. S. Schindler, 2011. Business Research Methods. $8^{\text {th }}$ ed., New York: McGraw-Hill.

Cummings, J. N. 2004. 'Work Groups, Structural Diversity, and Knowledge Sharing in a Global Organization'. Management Science, 50 (3), 352-364.

Davis, F. D, R. P. Bagozzi, and P. R. Warshaw, 1989. 'User Acceptance of Technology: A Comparison of Two Theoretical Models'. Management Journal of Management Studies 47 (1), 27-54.

Fishbein, M., and I. Ajzen, 1975. Belief, Attitude, Intention and Behavior: An Introduction to Theory and Research. California: Addison-Wesley.

Galia, F. 2006. 'An Invisible Frontier? IntrinsicExtrinsic Motivations and Knowledge Sharing in Firms'. Workshop on Motivation Foundations of Knowledge Sharing, Copenhagen.

Gross, N., W. S. Mason, and A. W. McEachern. 1958. Exploration in Role Analysis: Studies of The School Superintendency Role, New York: Wiley.

Hair, J.F. Jr., R. E. Anderson, R. L. Tatham, W. C. Black, and B. J. Babin, 2010. Multivariate Data Analysis: A Global Perspective, $7^{\text {th }}$ edition, New Jersey: PrenticeHall.

Hallin, C. A., and E. Marnburg, 2006. 'Knowledge Management in The Hospitality Industry: A Review of Empirical Research', Tourism Management, 29 (2), 366-381.
Hartono, J., 2007. Sistem Informasi Keperilakuan. Yogyakarta: Penerbit Andi.

Hsu, C. L., and J. C. C. Lin, 2008. 'Acceptance of Blog Usages: The Roles of Technology Acceptance, Social Influence and Knowledge Sharing Motivation'. Information and Management, 45 (1), 65-74.

Hu, M. L. M., J. Horng, dan Y. C. Sun, 2009, 'Hospitality Teams: Knowledge Sharing and Service Innovation Performance', Tourism Management, 30 (1), 41-50.

Indonesia Statistic Bureau (Badan Pusat Statistik). Provinsi Maluku. 2016.

Ismail, W. K. W., K. M. Nor, and T. Marjani, 2009. 'The Role of Knowledge Sharing Practice in Enhancing Project Success'. Journal Contemporary Research in Business, 1 (7): 34-52.

Kinch, J. W. 1973. Social Psychology. San Fransisco: McGraw-Hill.

Korzaan, M. L. 2003. 'Going with the Flow: Predicting Online Purchase Intentions', Journal of Computer Information Systems, 43 (4), 25-31.

Kruglanski, A. W. 1978. "Endogenous Attribution and Intrinsic Motivation". In Greene, D. (Ed ). Hillsdale, NJ: Lawrence Erlbaum.

Kwok, S. H., and S. Gao, 2005. 'Attitudes Towards Knowledge Sharing Behavior', Journal of Computer System, 46 (2), 45-51.

Liebowitz, J. 2003. 'A Knowledge Management Strategy for the Jason Organization: A Case Study', Journal of Computer Information Systems, 44 (2), 1-5.

Lin, H. F. 2007. 'Effects of Extrinsic and Intrinsic Motivation on Employee Knowledge Sharing Intentions', Journal of Information Science, 33 (2), 135-149.

Liao, C., H. N. Lin, and Y. P. Liu, 2010. 'Predicting The Use of Pirated Software: A Contingency Model Integrating Perceived Risk with The Theory of Planned Behavior', Journal of Business Ethics, 91 (2), 237-252.

Lovelock, C. H. 1983. 'Classifying Services to Gain Strategic Marketing Insights', Journal of Marketing, 47 (Juli): 9-20.

Media Indonesia. 2009.

$\mathrm{http} / / / \mathrm{www} . m e d i a i n d o n e s i a . c o m /$ mediatravelista /index.php/read/2009/11/27/107/1/Maluku- 
Rintis-Desa-Wisata diakses tanggal 20 Maret 2014.

Morrison, E. W. 1994. 'Role Definitions and Organizational Citizenship Behavior: The Importance of The Employee's Perspective'. Academy of Management Journal, 37 (6), 1543-1567.

Murray, S. R., and J. Peyrefitte. 2007. 'Knowledge Type and Communication Media Choice in The Knowledge Transfer Process'. Journal of Managerial Issues, 19 (1), 111-133.

Nooteboom, B. 2000. 'Learning by Interaction: Absorptive Capacity, Cognitive Distance and Governance', Journal of Management and Governance, 4 (1): 69-92.

O’Dell, C., and C. J. Grayson, 1998. 'If Only We Knew What We Know: Identification and Transfer of Internal Best Practice'. California Management Review, 40 (3), 154-174.

Ramayah, T., A. M. Nasurdin, M. N. Noor, and Q. B. Sin, 2004. 'The Relationships Between Belief, Attitude, Subjective Norm, and Behavior Towards Infant Food Formula Selection: The Views of The Malaysian Mothers. Gadjah Mada International Journal of Business, 63 (3), 405-418.

Ruggles, R. 1998. 'The State of The Nation: Knowledge Management in Practice', California Management Review, 40 (3): 8089.

Robertson, M., J. Swan, and S. Newell, 1996. 'The Role of Networks in the Diffusion of Technological Innovation', Journal of Management Studies, 33 (3), 335-361.

Ryan, R. M., and E. L. Deci. 2000. 'Intrinsic and Extrinsic Motivation: Classics Definition and New Directions'. Contemporary Educational Psychology, 25 (1), 54-67.

Ryu S., S. H. Ho, and I. Han, 2003. 'Knowledge Sharing Behavior of Physicians in
Hospitals', Expert Systems with Applications, 25 (1), 113-122.

Szulanski, G. 1995. 'Unpacking Stickiness: An Empirical Investigation of the Barriers to Transfer Best Practice Inside the Firm', Academy of Management Proceedings, 1, 437-441.

Teh, P-L., and C. C. Yong, 2011. 'Knowledge Sharing in IS Personel: Organizational Behavior's Perspective', Journal of Computer Information System, 51 (4), 1121.

Vallerand, R. J., and R. Bissonnette, 1992. 'Intrinsic, Extrinsic and A Motivational Styles as Predictors of Behavior: A Prospective Study', Journal of Personality, 60 (3), 599-620.

Van Dyne, L., and J. A. LePine, 1994. 'Helping and Voice Extra-Role Behaviors: Evidence of Construct and Predictive Validity', Academy of Management Journal, 41 (1), 108-119.

Wasko, M. M., and S. Faraj, 2005. 'Why Should I Share? Examining Social Capital and Knowledge Contribution in Electronic Networks of Practice'. MIS Quarterly, 29 (1), 35-57.

Wu, W. Y., and B. M. Sukoco, 2010. 'Why should I share? Examining consumers' motives and trust on knowledge sharing'. Journal of Computer Information System, 50 (4), 11-19.

Zahra, S. A., and G. George, 2002. 'Absorptive Capacity: A Review, Reconcep-tualization, and Extension'. Academy of Management Review, 27 (2), 185-203.

Zeithaml, V. A., and M. J. Bitner, 2003. "Service Marketing: Integrating Customer Focus Across The Firm". International Edition. New York: McGraw-Hill Companies. Inc. 


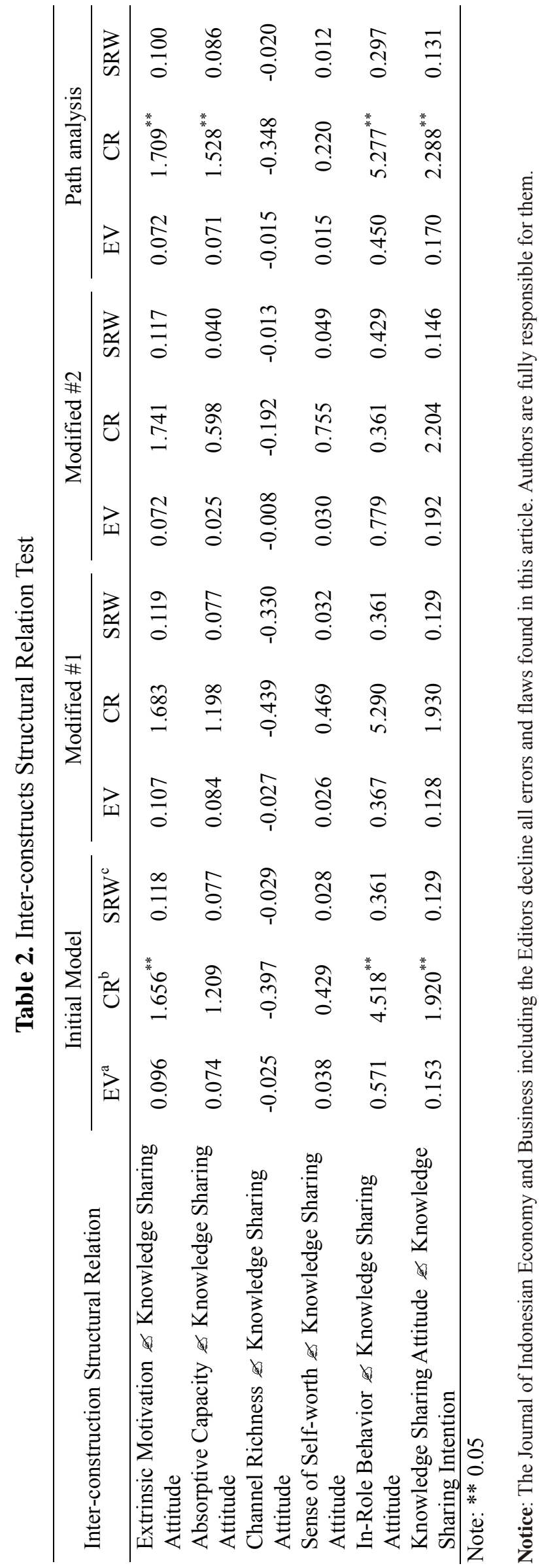

